\title{
Has the introduction of laparoscopic Heller myotomy altered the treatment paradigm of achalasia?
}

\author{
Lorenzo E Ferri MD FRCSC ${ }^{1}$, Liane S Feldman MD FRCSC FACS ${ }^{1}$, Donna Stanbridge RN ${ }^{1}$, \\ Serge Mayrand MD FRCP ${ }^{2}$, Gerald M Fried MD FRCSC FACS ${ }^{1}$
}

\begin{abstract}
LE Ferri, LS Feldman, D Stanbridge, S Mayrand, GM Fried. Has the introduction of laparoscopic Heller myotomy altered the treatment paradigm of achalasia? Can J Gastroenterol 2005;19(10):619-623.
\end{abstract}

\begin{abstract}
Although surgical myotomy is well established as the most effective and durable treatment for achalasia, wide acceptance of this procedure as a first-line treatment has been hampered by perceived invasiveness and morbidity. Laparoscopic myotomy has significantly reduced surgical trauma and morbidity while maintaining effectiveness. The effect of laparoscopic myotomy on the treatment pattern for achalasia is not currently known. All patients undergoing surgical myotomy in Quebec from 1997 to 2002 were identified from the Régie de l'assurance maladie du Québec billing database; previous endoscopic treatment was documented from 1990 to the time of surgery. Patients were divided into two groups (prelaparoscopy and postlaparoscopy) defined by the approximate date when laparoscopic myotomy became generally available in Quebec. A questionnaire examining treatment preference for achalasia was sent to all Quebec gastroenterologists. The number of myotomies performed in Quebec remained stable (prelaparoscopy $=28.7 /$ year; postlaparoscopy $=33 /$ year $)$, but were performed on an older population. The rate of preoperative endoscopic treatment did not differ from prelaparoscopy $(29.2 \%)$ to postlaparoscopy $(23.3 \%)$. However, the time interval between the last endoscopy and myotomy diminished significantly. Questionnaire response rate was 41\% (60 of 147). Although myotomy was recognized as the most effective treatment (54 of 60), only 22 of 60 gastroenterologists would refer a healthy patient for myotomy as initial treatment. Other choices included dilation (33 of 60 ), Botulinum toxin (two of 60) or calcium channel blockade (three of 60 ). Despite a decrease in time interval between endoscopic treatment and surgery, no decrease in the rate of existing endoscopic therapies occurred after laparoscopic myotomy became widely available. The benefits and minimal risks associated with laparoscopic myotomy need to be more effectively communicated by referring physicians.
\end{abstract}

Key Words: Achalasia; Balloon dilation; Botulinum toxin; Heller myotomy; Laparascopy

A chalasia is a rare esophageal motility disorder characterAized by uncoordinated contractions of the esophagus leading to ineffective swallowing. Relief of dysphagia represents the primary treatment goal for patients with achalasia. Medical, endoscopic and surgical treatments have all been employed, with varying success rates. Despite minimal risk, pharmacological calcium channel blockade has generally not been effective for relief of dysphagia (1). Widely used endoscopic treatment options include Botulinum toxin injection

\section{L'introduction de la myotomie de Heller par laparoscopie a-t-elle modifié le paradigme thérapeutique de l'achalasie?}

Bien qu'il soit bien établi que la myotomie chirurgicale soit le traitement le plus efficace et le plus durable de l'achalasie, l'acceptation généralisée de cette intervention comme traitement de première ligne a été gênée par la perception d'effractivité et de morbidité s'y associant. La myotomie par laparoscopie a réduit de manière considérable le traumatisme chirurgical et la morbidité du traitement tout en en conservant l'efficacité. On ne connaît pas encore l'effet de la myotomie par laparoscopie sur le schéma thérapeutique de l'achalasie. Tous les patients qui ont subi une myotomie chirurgicale au Québec entre 1997 et 2002 ont été repérés dans la base de données de facturation de la Régie de l'assurance maladie du Québec, et le traitement endoscopique antérieur a été documenté entre 1990 et le moment de l'opération. Les patients ont été séparés en deux groupes (avant et après l'introduction de la laparoscopie) définis par la date approximative à laquelle la myotomie par laparoscopie est devenue généralisée au Québec. Un questionnaire portant sur la préférence de traitement de l'achalasie a été expédié à tous les gastroentérologues du Québec. Le nombre de myotomies exécutées au Québec est demeuré stable (avant l'introduction de la laparoscopie : 28,7 patients par année; après : 33 par année), mais cette intervention était effectuée auprès d'une population plus âgée. Le taux de traitement endoscopique préopératoire n'a pas changé avant $(29,2 \%)$ et après $(23,3 \%)$ l'introduction de la laparoscopie, mais l'intervalle entre la dernière endoscopie et la myotomie a considérablement diminué. Le taux de réponse au questionnaire s'est élevé à 41 \% (60 sur 147). La myotomie a été reconnue comme le traitement le plus efficace (54 sur 60), mais seulement 22 des 60 gastroentérologues aiguilleraient un patient en santé vers un traitement initial par myotomie. Les autres choix incluaient la dilatation (33 sur 60), la toxine Botulinum (deux sur 60) ou l'inhibition calcique (trois sur 60). Malgré la diminution de l'intervalle entre le traitement endoscopique et l'opération, le taux de thérapies endoscopiques existantes n'a pas diminué après la généralisation de la myotomie par laparoscopie. Les bénéfices et les risques minimes associés à la myotomie par laparoscopie doivent être communiqués avec plus d'efficacité par le médecin traitant.

and pneumatic dilation. While initial response rates for intramuscular Botulinum toxin are as high as $70 \%$, the response is short lived, with a recurrence rate approaching $90 \%$ at six months (2). Long-term results of endoscopic disruption of the muscularis layer by pneumatic dilation are also suboptimal, with permanent success in only $40 \%$ to $50 \%$ of patients (3). Due to the intramural inflammation and scarring resulting from endoscopic therapies, the risk for mucosal injury is potentially increased if a subsequent myotomy is performed $(4,5)$.

${ }^{1}$ Division of General Surgery and Steinberg-Bernstein Centre of Minimally Invasive Surgery; ${ }^{2}$ Department of Gastroenterology, McGill University Health Centre, McGill University, Montreal, Quebec

Correspondence: Dr Gerald M Fried, Montreal General Hospital, Room L9-309, Montreal, Quebec H3G 1A4. Telephone 514-934-8044,

fax 514-934-8438, e-mail gerald.fried@mcgill.ca

Received for publication April 1, 2005. Accepted June 3, 2005 


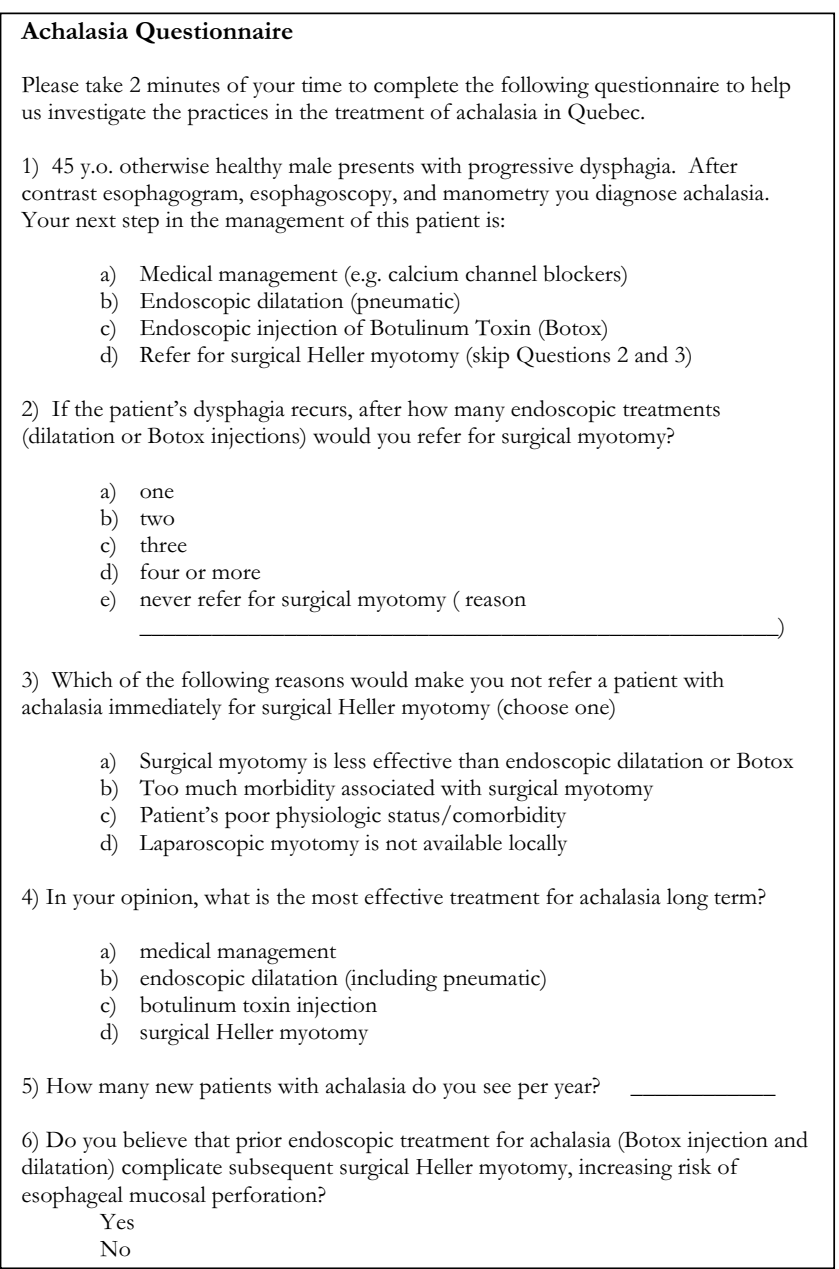

Figure 1) Six-question survey sent to gastroenterologists in Quebec. y.o Year old

Surgical myotomy is well recognized as the most effective and longest lasting treatment option for patients with achalasia (6). Traditionally, this has been performed through a thoracotomy, with excellent long-term symptomatic relief achieved in over $90 \%$ of patients $(7,8)$. The surgical morbidity and long recovery associated with this incision have presented obstacles to the acceptance of this surgical approach as a first-line treatment option for patients newly diagnosed with achalasia. Therefore, despite the effective superiority of surgical myotomy, many patients and physicians have opted for nonsurgical treatment. With the successful application of minimally invasive surgical techniques to the management of achalasia, laparoscopic myotomy has significantly diminished the morbidity of the procedure and has improved recovery, while maintaining its effectiveness $(6,9)$. Although there are reports of retrospective, single institution-based studies (10) demonstrating a change in the treatment patterns in achalasia, these studies are biased by the fact that the patients are referred for surgical myotomy. It is therefore currently unknown how the advent of minimally invasive surgery has affected the general treatment patterns of achalasia.

We sought to determine the effect of the availability of laparoscopic myotomy on the treatment paradigm for achalasia. Furthermore, we wished to identify referring physicians' biases in the management of this disease. To address these issues, both local and regional patterns of management were examined with particular attention to the number of endoscopic treatments before surgical myotomy.

\section{METHODS}

Local patterns of treatment for achalasia were assessed by reviewing prospectively collected data on all patients undergoing laparoscopic Heller myotomy at the McGill University Health Centre, Montreal, Quebec. The numbers and types of endoscopic intervention before surgery were recorded and compared between years. All laparoscopic Heller myotomies included a partial anterior $180^{\circ}$ fundoplication and were performed or supervised by a single surgeon (GMF).

To determine regional treatment patterns, all patients undergoing surgical myotomy from 1997 to 2002 in Quebec were identified from the Régie de l'assurance maladie du Québec (RAMQ) billing administrative database. Index patients were identified by the billing code for surgical myotomy (transabdominal or thoracic esophagocardiomyotomy Heller). No distinction is made in the database between minimally invasive and open techniques. All patients undergoing Heller myotomy, based on this billing code, were assumed to have had a diagnosis of achalasia. Data obtained from the database included age, sex and date of myotomy. Previous endoscopic procedures for each index patient were noted from 1990 to 2002. No separate billing code exists for pneumatic dilation or Botulinum toxin injection. Therefore, for the purpose of the present study, all procedures with a code for esophagogastroduodenoscopy with intervention - dilation, injection or ligation - were assumed to be an endoscopic treatment for achalasia in patients who had a subsequent Heller myotomy. The date of previous or subsequent endoscopic procedures was recorded for each index patient. Patients were divided into two groups (prelaparoscopy and postlaparoscopy) defined by the approximate date when laparoscopic Heller myotomy became generally available in Quebec (January 1, 2000).

To assess the referring physicians' biases in the treatment of achalasia, a six-question survey (Figure 1) exploring the management of achalasia was sent to all gastroenterologists listed in the 2002 Quebec specialist medical directory. Questionnaires were mailed in both English and French. Nonresponse prompted the mailing of a second questionnaire after six weeks.

Data are presented as median (range) unless otherwise stated. Statistical significance of differences was determined by $\chi^{2}$ for categorical variables and Mann-Whitney $U$ test for continuous variables. A difference was considered significant if a $\mathrm{P}$ value of less than 0.05 was obtained.

\section{Local treatment patterns}

\section{RESULTS}

A total of 38 patients underwent laparoscopic Heller myotomy at the Montreal General Hospital, Montreal, Quebec from June 1999 to April 2004. Overall, 47\% (18 of 38) of the patients had one or more endoscopic interventional procedures before referral for laparoscopic myotomy. Botulinum toxin injection alone was used in six patients, 10 had pneumatic dilation alone and two had both. The proportion of patients having endoscopic treatment before surgery declined from $70 \%$ in the first 10 patients (seven of 10 ) to $39 \%$ (11 of 28) subsequently ( $\mathrm{P}=0.19$ ).

\section{Regional treatment patterns}

One hundred eighty-five patients were identified in the RAMQ database to have undergone a Heller myotomy from 1997 to 2002 (Table 1). The number of procedures per year 
TABLE 1

Patient characteristics and treatment of 185 patients undergoing surgical myotomy from 1997 to 2002 in Quebec, divided into two groups based on the approximate date of general availability of minimally invasive Heller myotomy (January 1, 2000)

\begin{tabular}{lccc}
\hline & $\begin{array}{c}\text { Prelaparoscopy } \\
\text { (1997 to 1999) }\end{array}$ & $\begin{array}{c}\text { Postlaparoscopy } \\
\text { (2000 to 2002) }\end{array}$ & P \\
\hline $\mathrm{n}$ & 86 & 99 & \\
Age (years) & $46(11-83)$ & $51(13-83)$ & 0.04 \\
Sex (male/female) & $45 / 41$ & $47 / 52$ & 0.51 \\
Prior endoscopic therapy, $\mathrm{n}(\%)$ & $14(29)$ & $23(23)$ & 0.24 \\
Interval (months)* $_{\text {Concurrent fundoplication, } \mathrm{n}(\%)}$ & $7(0.25-57)$ & $3(0.25-18)$ & 0.04 \\
\hline
\end{tabular}

*Time from last endoscopic intervention to surgical myotomy

remained stable over this period (prelaparoscopy $=28.7 /$ year, postlaparoscopy $=33 /$ year). Patients were older in the postlaparoscopy period. The proportion of patients undergoing preoperative endoscopic treatment did not significantly differ between prelaparoscopy (29\%) and postlaparoscopy (23\%) periods (Figure 2); however, the median time interval between the last endoscopic treatment and myotomy decreased from seven to three months. The rate of concurrent fundoplication increased significantly, from $11 \%$ to $52 \%(\mathrm{P}<0.01)$. Seven patients had treatment failure severe enough to elicit an additional postoperative endoscopic procedure or a repeat myotomy. A fundoplication was present in two of seven failures (29\%), similar to the rate in the overall cohort (60 of $185,32 \%$ ).

\section{Survey of gastroenterologists}

A total of 147 gastroenterologists were listed in the Quebec Collège des Médecins directory. Response rate after the second mailing was $41 \%$ (60 of 147). Although $90 \%$ of respondents agreed that surgical myotomy represented the most effective long-term treatment for achalasia (Figure 3A), only 37\% would refer a newly diagnosed patient for immediate Heller myotomy (Figure 3B). Of the 55\% choosing pneumatic dilation as first-line therapy, $58 \%$ would refer the patient for surgical opinion after a single failed dilation, while $8 \%$ would never refer to surgery (Figure $3 \mathrm{C}$ ). In those who would not refer for immediate surgery, $73 \%$ cited patient comorbidity and $21 \%$ cited surgical trauma/morbidity as the reason for alternate treatment (Figure 3D). Among physicians who treat more than four new patients with achalasia per year, five of eight would refer for immediate surgical myotomy as the first-line therapy.

\section{DISCUSSION}

We sought to determine the impact of the introduction of minimally invasive Heller myotomy for achalasia on the treatment patterns for this disease. An assessment of the local referral patterns has demonstrated that our own institution's increasing experience in minimally invasive myotomy coincided with a reduction in the percentage of patients with previous endoscopic therapy. Although not reaching statistical significance, we found that the proportion of patients undergoing previous therapy was highest in the first 10 patients $(70 \%)$ compared with subsequent patients (39\%). We believe this is mainly due to a shift in the treatment paradigm employed by the gastroenterologist in our group (SM), from whom the majority of our

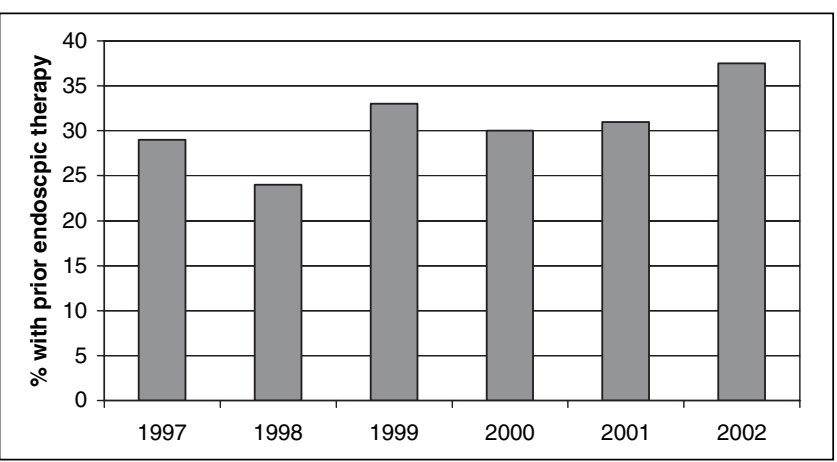

Figure 2) Annual rate of previous endoscopic intervention in all patients undergoing Heller myotomy in Quebec from 1997 to 2002 $(P=$ not significant $)$

referrals originated. As our experience with laparoscopic Heller myotomy grew, patients who were referred for confirmation and management of their achalasia underwent operation without further endoscopic procedures, representing a change in management. This did not affect the treatment patients received before referral to our centre. This finding is similar to that reported by Patti et al (10) in which a gradual, nonsignificant increase in untreated patients being referred for myotomy was reported.

Data from these single-centre studies may be biased by the fact that the patients are often referred precisely for the surgical procedure; thus, data may be skewed by local referral patterns. To eliminate this selection bias, we investigated the regional referral patterns by two additional methods. RAMQ demonstrated that the absolute number of myotomy procedures remained stable (approximately 30 per year) over a fiveyear period centred on an arbitrary date at which minimally invasive surgery for achalasia was presumed to have become generally available (January 1, 2000). Unfortunately, the RAMQ billing code does not distinguish between open and minimally invasive procedures. The proportion of patients receiving previous endoscopic therapy also remained stable over this time period. Of interest was that the rate of previous endoscopic therapy in the RAMQ database was lower than that in our own institution. Some patients received treatment before 1997, and a few received therapy outside of the province. In addition, as with all administrative databases, miscoding and under-representation of cases or procedures is commonplace (11), and represents an inherent weakness in this type of study. Particular to the present study, no separate billing code for the two commonly used endoscopic therapies (Botulinum toxin injection and pneumatic dilation) exists. Rather, a catchall code for any esophageal endoscopic intervention (injection, dilation, sclerosis or ligation) is used. Clearly, some endoscopic therapies may have been miscoded, resulting in under-reporting. Nonetheless, it is fair to assume that this potential miscoding would be equally distributed across the years under study; thus, trends in treatment should remain valid.

Although we found no change in the absolute number of myotomies or in the rate of previous endoscopic therapy, Heller myotomy was performed on an older population and at a shorter time interval from the last endoscopic treatment in the postlaparoscopy group. These changes suggest that the threshold for referral to myotomy may have diminished concurrently with the introduction of minimally invasive myotomy. Despite 


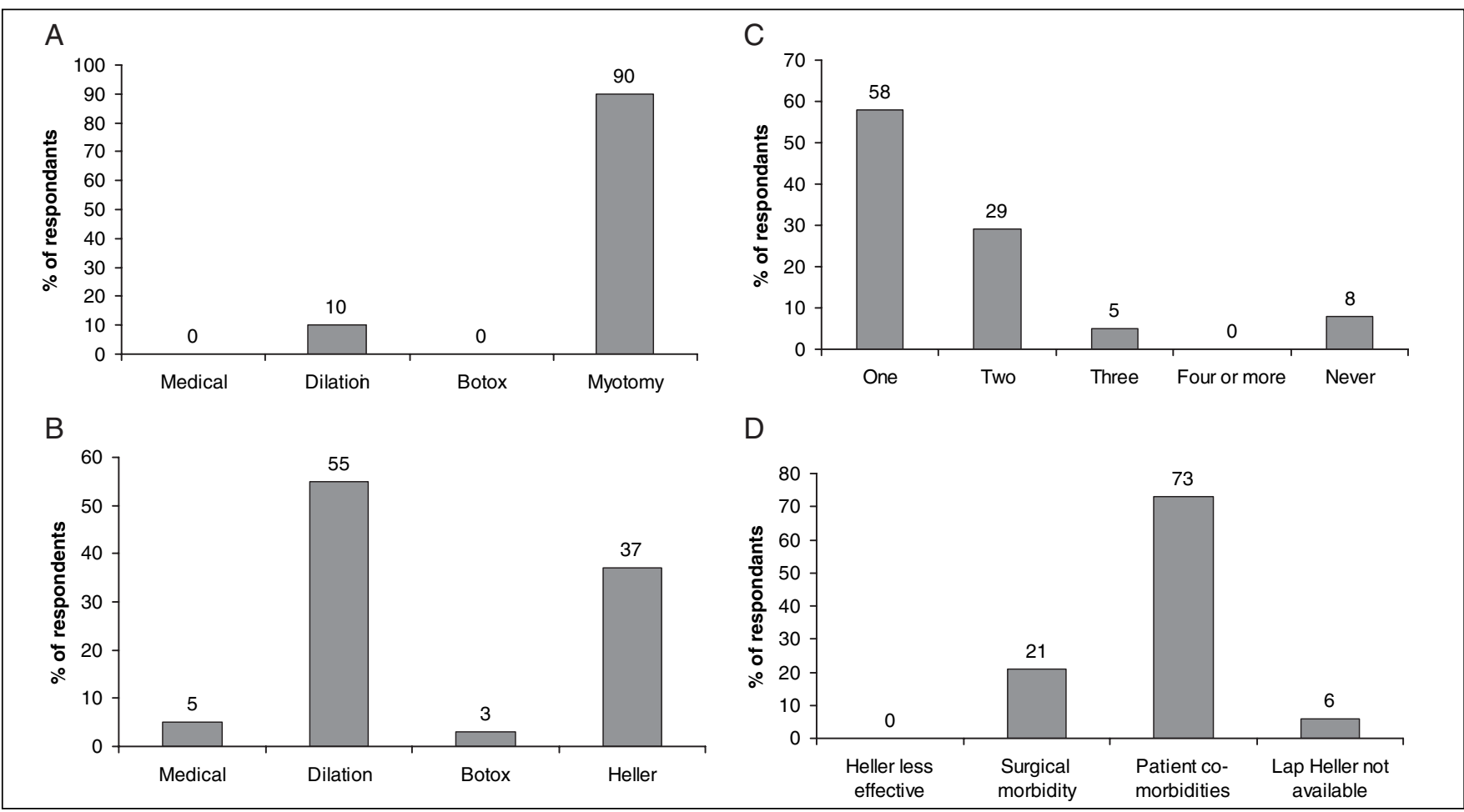

Figure 3) Responses from a questionnaire investigating the prevailing biases in the treatment of achalasia sent to all Quebec gastroenterologists. A Referring physicians' perception of the most effective long-term treatment for achalasia. The vast majority considered surgical myotomy to be the most effective treatment. B First-line treatment for achalasia according to responses from a questionnaire to all Quebec gastroenterologists. C Referring physician-based threshold for referral of an achalasia patient for surgical myotomy (number of endoscopic interventions to be attempted before to surgical referral). D Reasons for nonreferral for surgical myotomy. The majority of responding gastroenterologists deemed the surgical procedure too morbid for a given patient's physiological state. Botox Botulinum toxin; Lap Laparoscopic

ongoing controversy surrounding the use of fundoplication with myotomy, the proportion of procedures, including an antireflux procedure, increased approximately fivefold during the study period. Whether this reflects an increase in the use of a transabdominal over a transthroacic approach is not available in the RAMQ database. However, this finding is consistent with a recent prospective randomized trial supporting routine fundoplication after myotomy (12).

We assessed the predominant treatment paradigm for achalasia, from the referring physicians' perspective, with a sixquestion survey sent to all gastroenterologists in Quebec. Although the vast majority of respondents agreed that surgical myotomy represented the most effective and longest lasting treatment for achalasia, only slightly more than one-third referred newly diagnosed patients for immediate surgery. Rather, patients are offered endoscopic therapies (predominantly pneumatic dilation). Several studies (4-5,13) suggest that preoperative endoscopic treatment may adversely affect and complicate a subsequent Heller myotomy. Increased intramural fibrosis from either Botulinum toxin injection or endoscopic dilation may obliterate the natural submucosal plane, potentially increasing the risk for mucosal injury during the myotomy (14). Indeed, more than $40 \%$ of responding gastroenterologists agreed that previous endoscopic therapy increases the risk of mucosal injury in the case of a subsequent surgical myotomy. Quebec gastroenterologists favouring immediate referral for Heller myotomy were more likely to believe that preoperative endoscopic therapy complicates subsequent surgical treatment. Reasons cited for nonsurgical primary treatment of achalasia centred on the perceived morbidity of the procedure for a given patient's physiological state. This bias likely persists from the open transthoracic era despite several studies demonstrating the safety, low morbidity and rapid recovery of minimally invasive Heller myotomy.

We have attempted to detect a shift in the treatment paradigm of achalasia over a period encompassing the approximate date of the general availability of minimally invasive Heller myotomy in Quebec. Despite a slight decrease in the threshold for referral for surgical myotomy and an understanding among referring physicians that myotomy represents the most effective therapy for achalasia, no difference in the overall rate of previous endoscopic treatment occurred in the period under study. The benefits and minimal risk of minimally invasive Heller myotomy need to be more effectively communicated to the referring gastroenterologists, as they often represent the first-line in the treatment of achalasia.

FUNDING: Supported by an unrestricted educational grant from Tyco Healthcare Canada.

\section{REFERENCES}

1. Bortolotti M. Medical therapy of achalasia: A benefit reserved for few. Digestion 1999;60:11-6.

2. Neubrand M, Scheurlen C, Schepke M, Sauerbruch T. Long-term results and prognostic factors in the treatment of achalasia with botulinum toxin. Endoscopy 2002;34:519-23. 
3. West RL, Hirsch DP, Bartelsman JF, et al. Long term results of pneumatic dilation in achalasia followed for more than 5 years. Am J Gastroenterol 2002;97:1346-51.

4. Patti MG, Feo CV, Arcerito M, et al. Effects of previous treatment on results of laparoscopic Heller myotomy for achalasia. Dig Dis Sci 1999;44:2270-6.

5. Bonavina L, Incarbone R, Reitano M, Antoniazzi L, Peracchia A. Does previous endoscopic treatment affect the outcome of laparoscopic Heller myotomy? Ann Chir 2000;125:45-9.

6. Patti MG, Pellegrini CA, Horgan S, et al. Minimally invasive surgery for achalasia: An 8-year experience with 168 patients. Ann Surg 1999;230:587-93.

7. Csendes A, Braghetto I, Mascaro J, Henriquez A. Late subjective and objective evaluation of the results of esophagomyotomy in 100 patients with achalasia of the esophagus. Surgery 1988;104:469-75.

8. Bonavina L, Nosadini A, Bardini R, Baessato M, Peracchia A. Primary treatment of esophageal achalasia. Long-term results of myotomy and Dor fundoplication. Arch Surg 1992;127:222-6.
9. Finley RJ, Clifton JC, Stewart KC, Graham AJ, Worsley DF. Laparoscopic Heller myotomy improves esophageal emptying and the symptoms of achalasia. Arch Surg 2001;136:892-6.

10. Patti MG, Fisichella PM, Perretta S, at al. Impact of minimally invasive surgery on the treatment of esophageal achalasia: A decade of change. J Am Coll Surg 2003;196:698-703.

11. Measuring quality, outcomes, and cost of care using large databases. Proceedings of the 6th Regenstrief Conference. Marshall, Indiana, 4-6 September 1996. Ann Intern Med 1997;127(8 Pt 2):665-774.

12. Richards WO, Torquati A, Holzman MD, et al. Heller myotomy versus Heller myotomy with Dor fundoplication for achalasia: A prospective randomized double-blind clinical trial. Ann Surg 2004;240:405-12.

13. Morino M, Rebecchi F, Festa V, Garrone C. Preoperative pneumatic dilatation represents a risk factor for laparoscopic Heller myotomy. Surg Endosc 1997;11:359-61.

14. Richardson WS, Willis GW, Smith JW. Evaluation of scar formation after botulinum toxin injection or forced balloon dilation to the lower esophageal sphincter. Surg Endosc 2003;17:696-8. 


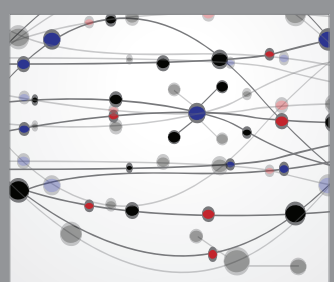

The Scientific World Journal
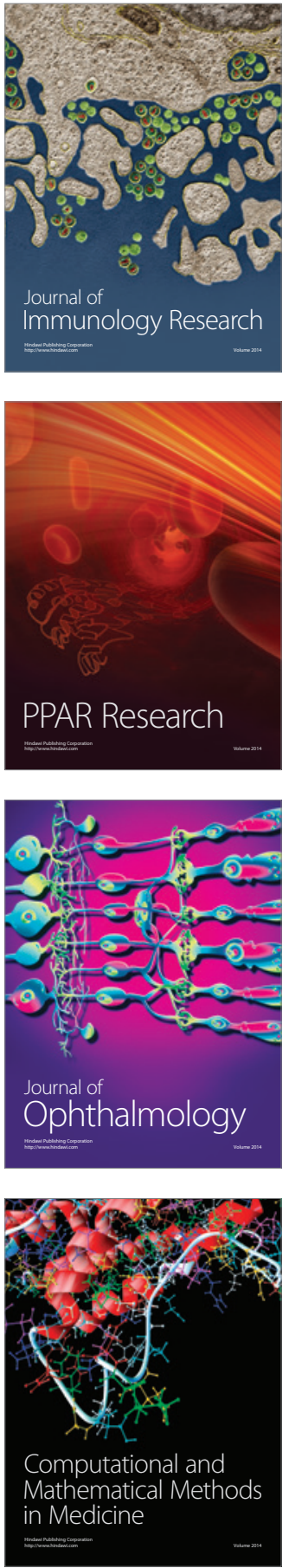

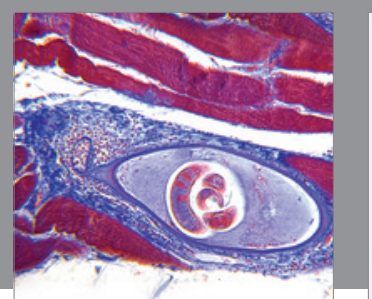

Gastroenterology Research and Practice

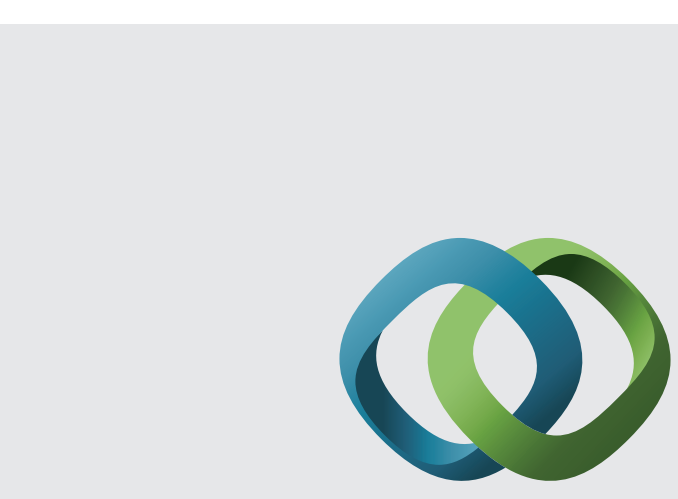

\section{Hindawi}

Submit your manuscripts at

http://www.hindawi.com
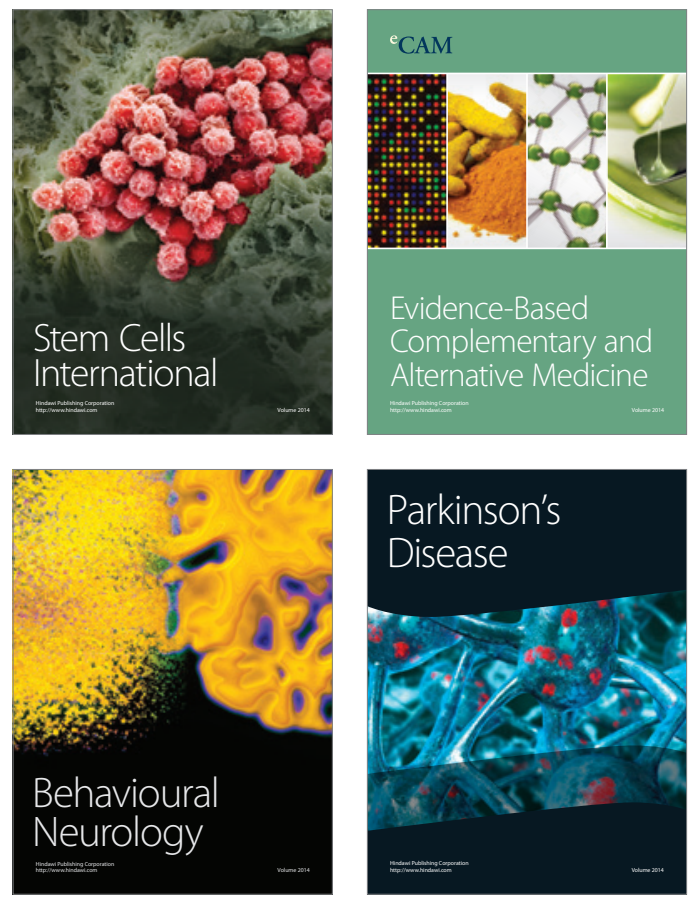
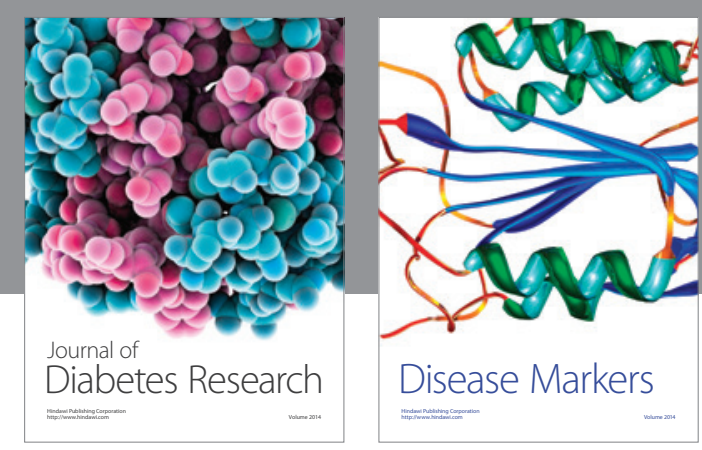

Disease Markers
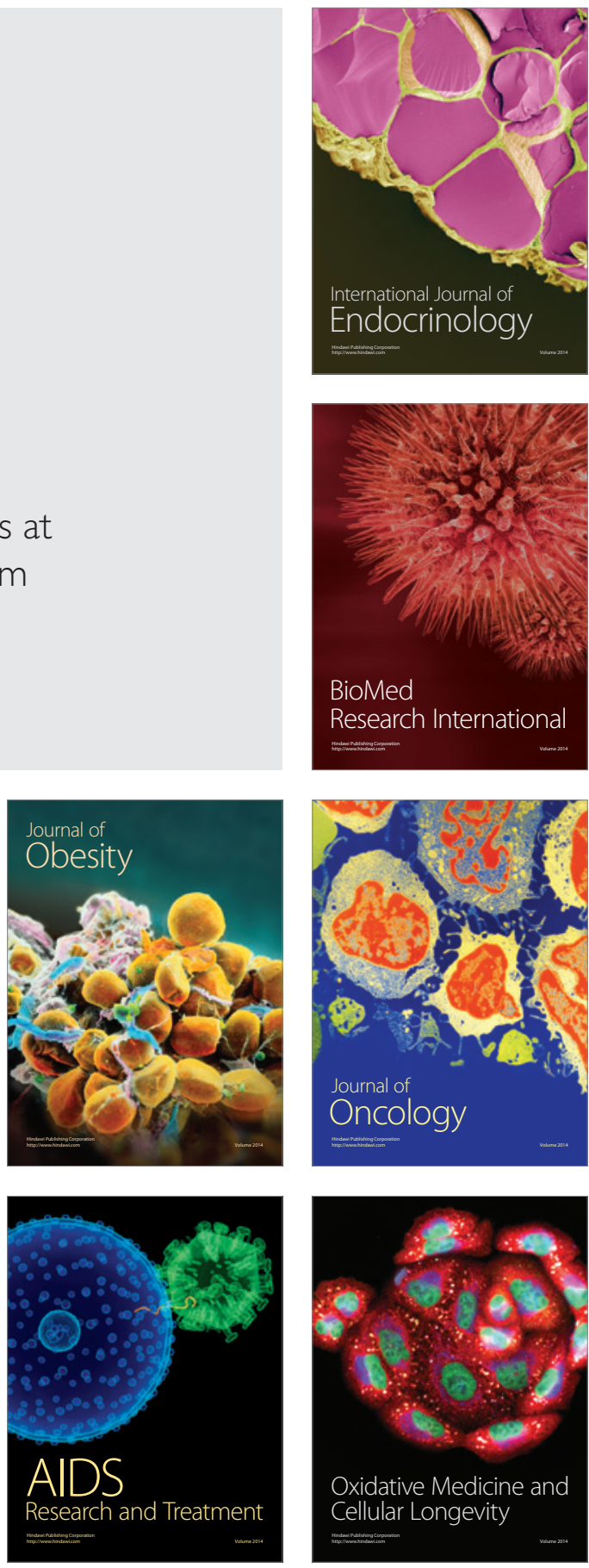